\title{
El derecho de retracto de los pasajeros en el transporte aéreo*
}

\section{Manuel Guillermo Sarmiento García*}

Sumario: Introducción. I. Conflicto de leyes y competencias en Colombia respecto a la regulación de los derechos de los pasajeros en el transporte aéreo. II. Desistimiento y retracto y su aplicación a las condiciones generales del transporte aéreo en Colombia.

\section{Introducción}

Resulta incuestionable que en las últimas décadas el derecho de los contratos ha sufrido una importante evolución, especialmente aquellos vínculos contractuales en que las relaciones de consumo ocupan un lugar destacado; me refiero fundamentalmente a los contratos que conllevan la prestación de un servicio público, donde los usuarios o consumidores, como parte contratante, tienen una posición privilegiada frente a la ley; dicha posición desborda muchas veces la regulación legal contenida en las normas de derecho privado que tipifican este tipo de contratos, los cuales, en cuanto tienen por objeto la prestación de un servicio público, dan lugar a un consumo masivo por parte de los ciudadanos; consumo que, por su impacto socio-

* Fecha de recepción: i6 de junio de 2016. Fecha de aceptación: 3 I de octubre de 2016.

Para citar el artículo: M. G. Sarmiento García, "El derecho de retracto de los pasajeros en el transporte aereo", Revista de Derecho Privado, Universidad Externado de Colombia, n. ${ }^{\circ} 3$ I, julio-diciembre de 20I6, 355-365. DoI: http://dx.doi.org/Io. I 8601/or $234366 . n_{3}$ I. I 2

Ponencia presentada en el seminario Le condizioni generali di trasporto del vettore aereo, Università di Roma 'La Sapienza', i 2 de mayo de 20 г6.

** Abogado. Director del Departamento de Derecho del Transporte, Universidad Externado de Colombia, Bogotá, Colombia. Contacto: manuel.sarmiento@uexternado.edu.co 
económico, ha dado lugar a un proteccionismo de los intereses de los usuarios ${ }^{\mathrm{I}}$, a menudo juzgado por las empresas prestadoras de los servicios como exagerado.

Es por ello que actualmente los derechos de los usuarios constituyen un tema importante en el análisis de los contratos, donde las relaciones de consumo influyen en forma determinante en el vínculo contractual, como sucede con la regulación del contrato de transporte aéreo, en la cual los derechos de los pasajeros se han convertido en uno de los aspectos fundamentales con miras a establecer las condiciones generales de dicho contrato.

Me propongo aquí presentar la situación que en materia de derechos de los pasajeros en el transporte aéreo se tiene actualmente en Colombia, concretamente el llamado derecho de retracto que tiene el pasajero para desistir de la celebración del contrato, analizando en primer lugar los conflictos de leyes que existen en Colombia respecto de la regulación de este derecho, que a su vez ha desatado un conflicto de competencias de las autoridades encargadas de aplicarlas. En efecto, las normas de derecho privado contenidas en el Código de Comercio y en las normas aeronáuticas chocan con las normas de derecho público consagradas en el Estatuto del Consumidor, habiéndose inclinado los tribunales, especialmente la Superintendencia de Industria y Comercio (en adelante, sic), en ejercicio de sus funciones jurisdiccionales, por aplicar el citado Estatuto para resolver los conflictos entre las aerolíneas y los pasajeros respecto al ejercicio del derecho de retracto, imponiéndoles a los transportadores aéreos cuantiosas multas por la violación de las normas de consumo en la ejecución del contrato de transporte aéreo.

Este análisis del conflicto de leyes y competencias en materia regulatoria nos conduce finalmente al estudio de la reciente reglamentación de la autoridad aeronáutica, donde se hace una diferencia entre los derechos de retracto y desistimiento, cuyo contenido, alcance y efectos resultan fundamentales en la configuración de los derechos de los pasajeros en el transporte aéreo, y su aplicación a las condiciones generales del contrato, que constituye la segunda parte de este trabajo.

\section{Conflicto de leyes y competencias en Colombia respecto a la regulación de los derechos de los pasajeros en el transporte aéreo}

Tradicionalmente en Colombia las funciones de regulación, inspección, vigilancia y control de la actividad aeronáutica en general, y del transporte aéreo en

I En este sentido, Mazeaud, D., "Las reformas del derecho francés de contratos", en Estudios de derecho civil. En memoria de Fernando Hinestrosa, t. II, Bogotá, Universidad Externado de Colombia, 20I4, 255, sostiene: "No hay duda de que la imposibilidad de negociar el contenido de sus contratos en la cual a menudo se encuentran los consumidores motivó al legislador a protegerlos contra las cláusulas abusivas que, con frecuencia, se caracterizan por otorgar un poder unilateral y exorbitante al profesional sobre la suerte del contrato, o por una desproporción entre los poderes y las posiciones contractuales, pero no afectan el equilibrio de las prestaciones”. 
particular, se encuentran en cabeza de la autoridad aeronáutica, de conformidad con lo establecido en el Código de Comercio, en la Ley 336 de I996 y en los reglamentos aeronáuticos, que a su vez son emitidos por dicha autoridad.

El Código de Comercio expedido en el año r97 I y la Ley 336 de r996, mediante la cual se expidió el Estatuto Nacional del Transporte, contienen una regulación muy exigua de los derechos de los pasajeros en el transporte aéreo, limitándose la legislación comercial a establecer los elementos básicos de la responsabilidad civil del transportador aéreo derivada del retardo en el cumplimientos de sus obligaciones y asignándole a la autoridad aeronáutica la facultad de expedir los reglamentos aeronáuticos (art. I782); mientras la Ley 336 en su artículo 68 les otorga a dichos reglamentos la categoría de fuente normativa del derecho aeronáutico, derogando de esta manera un antiguo concepto de la Sala de Consulta y Servicio Civil del Consejo de Estado que sostuvo la tesis en virtud de la cual estos reglamentos sólo podían referirse a aspectos técnicos de la navegación aérea, y por lo tanto la autoridad aeronáutica no tenía competencia para regular aspectos de orden jurídico vinculados con la actividad aeronáutica y la industria del transporte aéreo.

En consecuencia, la mayor parte de la regulación referida a los derechos de los pasajeros ha sido responsabilidad de la autoridad aeronáutica, quien ha expedido una reglamentación amplia y detallada del contenido y alcance de dichos derechos.

Así tenemos que los reglamentos aeronáuticos de Colombia, conocidos por la sigla RAC, en su parte tercera contienen la normatividad aplicable a las relaciones contractuales entre los transportadores aéreos y los pasajeros respecto a la celebración y ejecución del contrato, describiendo en forma pormenorizada tanto los derechos de los pasajeros y los correlativos deberes de los transportadores, como los derechos de estos y los respectivos deberes de los pasajeros.

Esta reglamentación, que influyó a su vez en la normatividad expedida por la Comunidad Andina de Naciones, antiguo Pacto Andino o Acuerdo de Cartagena, mediante la Decisión 6r9 de 2005, se refiere en forma específica a todas las fases de celebración y ejecución del contrato de transporte aéreo, desde la reserva del boleto o tiquete hasta el cumplimiento total de las obligaciones de resultado y garantía a cargo de los transportadores aéreos, reglamentando en forma detallada todo lo relacionado con la solicitud de reserva, el récord de reserva, su confirmación y reconfirmación por parte del pasajero y las consecuencias que tiene la omisión de la misma, la protección de la información entregada por el pasajero, el respeto de la reserva, la información sobre cambios a la reserva que debe suministrar la aerolínea, la adquisición del tiquete, su vigencia, el pago del mismo, el derecho que tiene el pasajero a desistir del viaje y sus efectos, el cumplimiento de las promociones ofrecidas por los transportadores, especialmente de los denominados "paquetes todo incluido", y en general todo lo relacionado con la expedición del pasabordo, el aviso para embarque, la admi- 
sión del pasajero, las facilidades para el embarque y desembarque, la conducción y tratamiento al pasajero, la reglamentación especial sobre pasajeros especiales: enfermos, dementes o menores, mujeres en estado de embarazo, las cancelaciones, interrupciones y demoras en los vuelos o sobreventas de boletos o tiquetes y las compensaciones a favor de los pasajeros en caso de que se presenten dichas situaciones; de tal forma que en principio parecería que esta reglamentación expedida por la autoridad aeronáutica en cumplimiento de sus facultades legales fuera suficiente para regular las relaciones contractuales entre los transportadores aéreos y los pasajeros.

Sin embargo, puesto que son los hechos sociales los que determinan fundamentalmente el contenido del derecho, como su principal fuente material ${ }^{2}$, hechos que avanzan más rápidamente que las fuentes formales, especialmente la ley, los reglamentos aeronáuticos no previeron una de las grandes revoluciones del transporte aéreo en su historia, a saber, el boleto o tiquete electrónico, que, junto con el paso del avión de pistón al de turbina y los sistemas computarizados de reservas, hace parte de las grandes transformaciones del transporte aéreo, las cuales lo han impulsado hasta convertirlo en el medio de locomoción más importante del siglo xxI.

La expedición de un boleto o tiquete electrónico por parte de las aerolíneas, que ya había sido prevista tanto en el Protocolo de Guatemala de I97 I $^{[3]}$ como en el Convenio de Montreal de $1999^{[4]}$, ha sido posible por la utilización de mecanismos de venta no tradicionales o a distancia, gracias a la aplicación de nuevas tecnologías, como son las plataformas de internet y los "call centers", que se han convertido en los principales canales de distribución de sus productos por parte de las aerolíneas, desplazando a las tradicionales agencias de viaje.

$\mathrm{Al}$ no haberse previsto en los reglamentos aeronáuticos estos mecanismos de venta de boletos o tiquetes aéreos por métodos no tradicionales o a distancia, este vacío de reglamentación fue llenado en Colombia por la Ley I480 de 20 i I, que contiene el Estatuto del Consumidor, el cual le asigna a la sic la facultad de regulación, inspección, control y vigilancia de todas las actividades relacionadas con las relaciones de consumo, regulando en forma específica las ventas de productos o servicios a través de mecanismos de venta no tradicionales o a distancia. Así se desprende claramente de lo estipulado en el artículo 2. ${ }^{\circ}$ de la Ley I480

2 En este sentido, Legaz y Lacambra, L., Filosofía del derecho, 5. ${ }^{a}$ ed., Barcelona, Bosch, i979, 5 I4, sostiene: "Como el Derecho tiene una dimensión existencial, las fuentes materiales del mismo han de ser también realidades existenciales, pues de lo contrario no podrían infundirle realidad y permanecería en estado de 'pensamiento', es decir, no sería derecho".

3 El artículo ir del Protocolo de Guatemala de i97 I establece que el documento de transporte individual o colectivo se puede sustituir por cualquier otro medio, siempre que se deje constancia de los requisitos exigidos para su expedición.

4 El artículo $3 \cdot^{\circ}$ del Convenio de Montreal de i 999 reprodujo exactamente la disposición del Protocolo de Guatemala de i97 I, anteriormente citado. 
de 20 I I, que al establecer el ámbito de aplicación del Estatuto del Consumidor dispone que el mismo será aplicable de manera general a todas las relaciones de consumo en todos los sectores de la economía, salvo cuando exista una regulación especial, caso en el cual se aplicará la regulación especial y, suplementariamente, las normas del Estatuto.

Queda entonces claro que, al no haber contemplado los reglamentos aeronáuticos las ventas de boletos o tiquetes aéreos a través de mecanismos no tradicionales o a distancia, se aplicaba en forma suplementaria el Estatuto del Consumidor en lo referente al ejercicio del derecho de retracto en este tipo de ventas, de conformidad con lo establecido en el artículo 47 de la Ley I480 de 20 I I.

Se presentó entonces con ocasión de la expedición del Estatuto del Consumidor un primer conflicto de leyes y de competencias respecto a la regulación de los derechos de los pasajeros; por una parte, la autoridad aeronáutica, con fundamento en lo establecido en el Código de Comercio y en la Ley 336 de I996, así como en el mismo Estatuto del Consumidor, afirma su competencia exclusiva para regular por medio de los reglamentos aeronáuticos todas las actividades relacionadas con el transporte aéreo; por la otra parte, la sic, igualmente, con fundamento en la Ley I 480 de 20 I I y en ejercicio de las funciones jurisdiccionales allí previstas, viene aplicando el Estatuto del Consumidor a las relaciones de consumo derivadas de los vínculos contractuales establecidos entre los transportadores aéreos y los pasajeros, concretamente en lo que se refiere al derecho de retracto que tiene todo consumidor de productos o servicios para dar por terminado unilateralmente el contrato.

Han sido precisamente los casos de venta de boletos o tiquetes aéreos por parte de aerolíneas colombianas a través de sus portales de internet los que han suscitado la intervención de la sic y la aplicación del Estatuto del Consumidor a las relaciones contractuales del transporte aéreo.

Por razones de tiempo, me voy a referir únicamente a dos de estos casos. Uno de ellos se presentó contra la aerolínea LaN Colombia Airlines S.A., que vendió a través de su portal de internet dos boletos o tiquetes aéreos al señor xx en la ruta Santa Marta-Bogotá-Santa Marta, quien al momento de la compra se equivocó al indicar la ruta, ya que lo que realmente quería era viajar en la ruta Bogotá-Santa Marta-Bogotá, razón por la cual se retractó de dicha compra, exigiendo el reembolso del boleto, a lo cual la aerolínea se negó, alegando que el procedimiento de retracto no se había hecho en forma correcta, si bien posteriormente, cuando el caso ya se encontraba en conocimiento de la sic, aceptó hacer el reintegro del valor de los boletos o tiquetes aéreos.

Durante el proceso judicial adelantado ante la sic y en la etapa de alegatos de conclusión, el apoderado de la aerolínea defendió la tesis en virtud de la cual los transportadores aéreos estaban sometidos a las normas contenidas en los reglamentos aeronáuticos y no era aplicable el Estatuto del Consumidor, y que en este caso específico, por tratarse de un boleto o tiquete no reembolsable, no procedía 
el reintegro de su valor, por cuanto el reglamento aeronáutico contemplaba en forma expresa esta excepción.

La sic en su decisión judicials no aceptó la defensa de la aerolínea y consideró que esta había vulnerado los derechos de información y ejercicio del derecho de retracto del pasajero, contemplados en los artículos 23 y 47 de la Ley I 480 de 20 I I, y le ordenó a la aerolínea reintegrar el valor del boleto o tiquete, por la suma de \$ 7 I 2.060, más los intereses causados por la utilización de la tarjeta de crédito, mediante la cual había sido adquirido, imponiéndole además a la aerolínea una multa a favor de la sic por la suma de \$6.I60.000, es decir, cerca de nueve veces el costo del reembolso del boleto.

El otro caso se presentó contra la aerolínea Avianca, que vendió a través de su portal de internet un boleto o tiquete aéreo al señor YY en la ruta CartagenaMedellín-Cartagena, quien al momento de la compra se equivocó al indicar la ruta, ya que lo que realmente quería era viajar en la ruta Medellín-CartagenaMedellín, razón por la cual se retractó de dicha compra, exigiendo el reembolso del boleto, a lo cual la aerolínea se negó, alegando que debía pagar una penalidad y la diferencia de tarifa, en caso de que aplicara, para efectos de proceder al cambio del tiquete aéreo.

Durante el proceso judicial adelantado ante la sic, el pasajero demandante alegó que la aerolínea había vulnerado su derecho a retractarse de la compra, el cual se había ejercido de conformidad con lo establecido en el Estatuto del Consumidor y por lo tanto tenía derecho a que se le reembolsara el valor del boleto o tiquete; mientras que la aerolínea, si bien no ejerció su derecho de defensa durante el trámite del proceso al no contestar la demanda, en respuesta a un derecho de petición formulado por el pasajero manifestó que el Estatuto del Consumidor no era aplicable a la venta de tiquetes aéreos, ya que para estos efectos las aerolíneas estaban sometidas a las normas contenidas en el Código de Comercio y en los reglamentos aeronáuticos, que no consagraban el derecho de retracto por parte del pasajero.

La sic en su decisión judicial ${ }^{6}$ consideró que la aerolínea había vulnerado el derecho de retracto del pasajero, consagrado en el artículo 47 de la Ley I 480 de 20 I I, y que no era de recibo la tesis de la aerolínea sobre las normas especiales que regulan el transporte aéreo, ya que era de aplicación el principio de interpretación favorable al consumidor, establecido en el artículo 34 de la misma Ley I480; por lo tanto, decretó la resolución del contrato de transporte aéreo celebrado entre el pasajero y la aerolínea, y le ordenó a esta reintegrar el valor del boleto o tiquete, por la suma de \$ I I 7.88o, debidamente indexada, imponiéndole

5 Ver Superintendencia de Industria y Comercio, Delegada para Asuntos Jurisdiccionales, Sentencia del 23 de enero de 2014 .

6 Ver Superintendencia de Industria y Comercio, Delegada para Asuntos Jurisdiccionales, Sentencia del 28 de julio de 2014 . 
además a la aerolínea una multa a favor de la sic por la suma de \$ 61.600.000, es decir, cerca de seiscientas veces el costo del reembolso del boleto.

En varios foros académicos y declaraciones de prensa7 la autoridad aeronáutica defendió su competencia exclusiva para regular, vigilar y controlar todas las actividades vinculadas con el transporte aéreo, y, concretamente frente a las decisiones de la sic, planteó la tesis de la diferencia conceptual entre el desistimiento y el retracto, afirmando que respecto de las condiciones generales del contrato de transporte aéreo sólo resultaba aplicable el desistimiento, y que este se encontraba regulado expresamente en el Código de Comercio y en los reglamentos aeronáuticos, por lo que no resultaba aplicable el derecho de retracto consagrado en el Estatuto del Consumidor.

Las decisiones judiciales de la sic en aplicación del Estatuto del Consumidor a las condiciones generales del contrato de transporte aéreo, especialmente en lo referente al ejercicio del derecho de retracto por parte del pasajero, preocuparon mucho a la industria del transporte aéreo, que impulsó en el Congreso de la República una ley con miras a resolver el conflicto de leyes y de competencias en esta materia, que no era sólo entre la autoridad aeronáutica y la sic, puesto que también se sumaba la Superintendencia de $\operatorname{Transporte}^{8}$, quien tiene facultades legales para inspeccionar, vigilar y controlar todos los modos de transporte, incluyendo el aéreo.

Finalmente el Congreso expidió la Ley i $55^{8}$ del ro de julio de 2012, conocida como Ley de Turismo, que, como lo comentamos en otra oportunidad, pretendió solucionar los conflictos de competencia entre la autoridad aeronáutica y la $\operatorname{sic}^{9}$.

7 En declaraciones para el periódico Portafolio, el 22 de julio de 20I4, el director de la Aerocivil sostuvo que el derecho de retracto en el transporte aéreo no aplica para tarifas promocionales, y refiriéndose a las decisiones adoptadas por la sIC afirmó categóricamente ser la Aerocivil la única entidad competente para dirimir los conflictos entre las aerolíneas y los pasajeros.

8 Ver Sarmiento García, M. G., "Los conflictos de regulación de los derechos de los pasajeros en el transporte aéreo", en Estudios de derecho civil. En memoria de Fernando Hinestrosa, t. II, Bogotá, Universidad Externado de Colombia, 2014, 539 ss.

9 En este sentido, Sarmiento García, ob. cit., 550, sostuvo: "Este conflicto de leyes en materia reguladora de los derechos de los pasajeros y de competencias entre las entidades administrativas encargadas de sus aplicación lo intentó solucionar el legislador al expedir la reciente Ley I 558 de ro de Julio de 2012 , conocida como Ley de Turismo, que establece en su artículo 25 que al sector del transporte aéreo en Colombia, solo le eran aplicables las normas de carácter aeronáutico contenidas en el Código de Comercio y en los reglamentos aeronáuticos, excluyendo expresamente de su aplicación las normas contenidas en el Estatuto del Consumidor expedido mediante la Ley I480 de 20 I I.

"Este artículo 25 de la Ley de Turismo ha sido objeto de muchas críticas, incluso algunos lo han calificado como un clásico 'mico', que en el argot parlamentario colombiano consiste en incluir en una ley una materia completamente ajena al objeto de regulación de la misma, que en el caso de la Ley I $55^{8}$ de 20 I 2 es la regulación de los servicios turísticos, los cuales deben diferenciarse de los servicios aéreos, así los usuarios de estos, en algunos casos sean igualmente turistas.

"Por otra parte si se revisa cuidadosamente el inciso $2 .^{\circ}$ de la disposición mencionada, allí solo se hace referencia a 'los proveedores y comercializadores de servicios aéreos', excluyendo expre- 
Resulta importante destacar que la Ley I $55^{8}$ de 2012 , y en especial su artículo 25, que fue objeto del análisis anterior, fue reglamentada por el Decreto reglamentario ro97 de 2014 , estableciendo los requisitos que deben cumplir los consumidores de servicios turísticos y aéreos para formular la reclamación directa ante los prestadores de dichos servicios, cuando se vulneren sus derechos como consumidores; afirmando dicho decreto la competencia que tiene la sIC para conocer las acciones jurisdiccionales de protección al consumidor previstas en el artículo 56 de la Ley i480 de 20 i I.

Ante la solución poco ortodoxa y atropellada del legislador colombiano consagrada en el artículo 25 de la Ley I $55^{8}$ de 20 I 2 , para dirimir el conflicto de leyes y competencias en materia de los derechos de los pasajeros en el transporte aéreo $^{\mathrm{IO}}$, le correspondió a la autoridad aeronáutica, en ejercicio de sus facultades legales, expedir una reglamentación especial sobre la venta de boletos o tiquetes aéreos por parte de las aerolíneas a través de mecanismos no tradicionales o a distancia, como los portales de internet y los "call centers", consagrando en forma específica el derecho de retracto por parte de los pasajeros, al cual se había opuesto, con el argumento de que ya existía la posibilidad de desistimiento.

Esta reglamentación está contenida en la Resolución or 375 del i I de junio de 2015 expedida por la Unidad Administrativa Especial de Aeronáutica Civil, incorporada a los reglamentos aeronáuticos, la cual en su artículo 2..$^{\circ}$, que modifica el numeral 3.IO.I.8 RAC, establece las diferencias entre desistimiento y retracto, a lo cual nos vamos a referir en la segunda parte de esta exposición.

\section{Desistimiento y retracto y su aplicación a las condiciones generales del transporte aéreo en Colombia}

La Resolución or 375 del I I de junio de 20 I 5 expedida por la autoridad aeronáutica, al adicionar la parte correspondiente de los reglamentos aeronáuticos que regulan los derechos de los pasajeros en el transporte aéreo, establece en su artículo $2 .^{\circ}$ una distinción conceptual entre las figuras de desistimiento y de retracto, que si bien producen las mismas consecuencias desde el punto de vista de los efectos finales del contrato, obedecen a diferentes causas y se ejercen en condiciones distintas.

Por una parte, la nueva reglamentación del desistimiento conserva los mismos lineamientos establecidos en el Código de Comercio $^{\text {II }}$ y en el reglamento

samente a los usuarios, por lo tanto atendiendo los principios que gobiernan la hermenéutica jurídica, habría que concluir que en materia de protección de los usuarios del transporte aéreo les son aplicables también las normas del Estatuto del Consumidor".

io En este sentido Sarmiento García, ob. cit., 55 I, sostuvo que la Ley I 558 de 20 i 2 corre el grave riesgo de ser declarada inconstitucional al violar el principio de la unidad de materia, que ha venido siendo aplicado permanentemente por la Corte Constitucional.

I I El artículo i 878 c.co.: "En los casos de desistimiento del viaje por parte del pasajero, las empresas de transporte público podrán fijar porcentajes de reducción en la devolución del valor del 
anterior $^{\mathrm{I} 2}$, como una forma de terminación unilateral del contrato de transporte aéreo por parte del pasajero, quien tiene la facultad exclusiva de desistir del viaje antes de su iniciación, dando aviso al transportador o a la agencia de viajes a través de la cual se celebró el contrato, con una antelación no inferior a veinticuatro horas a la realización del vuelo.

Este desistimiento del pasajero da lugar a la resolución del contrato de transporte aéreo, la cual trae como consecuencia el reembolso del valor del boleto o tiquete aéreo por parte del transportador o de la agencia de viajes en su caso, quienes tienen la facultad de efectuar una retención sobre dicho valor, de conformidad con el porcentaje acordado, que en todo caso no puede ser superior al Io\% del valor recibido por concepto de tarifa, excluyendo tasas, impuestos y tarifa administrativa. El reembolso debe hacerse en un término no mayor de treinta días calendario contados a partir de la fecha del desistimiento.

Sin embargo, este reembolso tiene una excepción, la cual no aplica cuando se trata de tarifas promocionales, que ya estaba prevista en el reglamento anterior, pero a la que el nuevo reglamento le agrega dos condiciones para su funcionamiento: primero, que, no obstante se trate de tarifas promocionales, el transportador haya ofrecido el reembolso; y segundo, que esas tarifas promocionales, para poder ser publicadas y ofrecidas, se deben haber registrado ante la Oficina de Transporte Aéreo de la autoridad aeronáutica, condición esta que ya había sido prevista en la Resolución 259 I del 6 de junio de 2013.

Esta novedad en la reglamentación del ejercicio del derecho al desistimiento es muy importante para la protección de los derechos de los pasajeros, ya que la aerolínea no puede escudarse en la excusa de que se trata de una tarifa promocional para no hacer la devolución del valor del tiquete; por el contrario, tiene la obligación de demostrar que dicha tarifa previamente había sido registrada ante la Oficina de Transporte Aéreo.

Pero lo más importante de esta resolución de la autoridad aeronáutica es el haber reconocido que además de la figura del desistimiento también resulta aplicable la del retracto, cuando se trate de ventas efectuadas a través de métodos no tradicionales o a distancia, establecidos en el Decreto I499 de 20I4, que era la misma regulación contemplada en el Estatuto del Consumidor que no había aceptado anteriormente.

Si bien desde el punto de vista semántico desistir y retractarse son dos conceptos idénticos, que además desde el punto de vista jurídico producen los mismos efectos ex tunc de resolución del contrato, como consecuencia de la terminación unilateral del mismo por parte del pasajero, la autoridad aeronáutica ha querido diferenciarlos, ya que provienen de causas diferentes y están sometidos a distintos requisitos.

pasaje, conforme a los reglamentos de la empresa, aprobados por la autoridad aeronáutica”.

I 2 Num. 3.ro.r.8 de los Reglamentos Aeronáuticos. 
Para el caso del desistimiento, este se aplica a todo tipo de ventas de boletos o tiquetes aéreos, ya sea directamente por la aerolínea o a través de agencias de viaje, por mecanismos tradicionales o métodos no tradicionales o a distancia, siempre y cuando no se trate de tarifas promocionales, caso en el cual no se produce la resolución del contrato, y dará lugar a una novación de las obligaciones asumidas por los contratantes ${ }^{13}$, que implica una sustitución del boleto o tiquete, con el cobro de una penalidad y de la diferencia de tarifa, si esta aplica.

En cambio, el retracto se aplica sólo para ventas de boletos o tiquetes aéreos efectuadas por métodos no tradicionales o a distancia previstos en el Decreto I499 de 20I4, ya se trate de tarifas ordinarias o promocionales, que da lugar a la resolución del contrato y al consiguiente reembolso del valor del boleto o tiquete al pasajero.

Veamos entonces qué diferencias importantes se presentan entre la regulación del derecho de retracto establecida en el Estatuto del Consumidor y la consagrada en este nuevo reglamento expedido por la autoridad aeronáutica.

En el Estatuto del Consumidor se estableció el derecho de retracto para una clase determinada de contratos que tipifica el artículo 47 de la Ley I480 de 20 I I, entre estos aquellos que dan lugar a ventas por métodos no tradicionales o a distancia, que en forma general están descritas en el artículo $5 .^{\circ}$, numerales I 5 y i 6 de la mencionada ley, mientras que la resolución de la autoridad aeronáutica hace referencia al Decreto I499 de 2014, reglamentario de la Ley I480, que en forma más amplia y pormenorizada describe este tipo de ventas, siendo las más utilizadas por las aerolíneas las realizadas a través de las plataformas de internet en sus páginas web y las ventas telefónicas mediante sus "call centers".

Sin embargo, desde el punto de vista de su ejercicio, el derecho de retracto consagrado en el reglamento aeronáutico es mucho más restrictivo de los derechos del pasajero que el establecido en el Estatuto del Consumidor. Mientras en este último el término para ejercerlo es de cinco días hábiles, contados a partir de la celebración del contrato, el reglamento solo estableció un término de cuarenta y ocho horas, a partir de la operación de compra, con la condición además de que para su efectividad solo puede ejercerse con una antelación no inferior a ocho días calendario a la fecha prevista para el viaje, si se trata de vuelos nacionales, o de quince días calendario, si son vuelos internacionales; de tal forma que si un pasajero compra un tiquete aéreo cinco días antes del vuelo, no puede ejercer el derecho de retracto, aspecto este que podría generar una nueva controversia entre la sic y la autoridad aeronáutica.

De igual forma, en el reglamento aeronáutico se estableció una retención a favor de la aerolínea, de $\$ 60.000$ para tiquetes nacionales y de US\$50 para

I 3 El artículo r697 c.co. en materia de novación dispone: "La novación es la sustitución de una nueva obligación a otra anterior, la cual queda por lo tanto extinguida". 
tiquetes internacionales, retención que no está prevista en el Estatuto del Consumidor en ningún caso a favor del prestador del servicio.

En lo que se refiere al plazo para efectuar el reembolso, tanto el Estatuto del Consumidor como el reglamento aeronáutico establecen un término de treinta días calendario, a partir de la comunicación del retracto.

Con la expedición de este reglamento aeronáutico y la regulación que en él se hace del derecho de retracto para ventas de boletos o tiquetes aéreos, queda claro que la norma aplicable para el transporte aéreo es dicho reglamento y no el Estatuto del Consumidor, de conformidad con lo establecido en el artículo $2 .^{\circ}$ de la Ley I480 de 20 I I, que al consagrar el principio de especialidad normativa excluye del ámbito de aplicación del Estatuto del Consumidor los contratos de transporte aéreo, sin que resulte viable, en mi opinión, el principio de favorabilidad establecido en el artículo 34 del Estatuto, que en algunas ocasiones ha sido mencionado por la sic para hacer prevalecer las normas de la Ley I480 de 20 I I sobre regulaciones especiales de la misma materia ${ }^{\mathrm{I} 4}$.

Para finalizar quisiera referirme a la opinión de un sector de la doctrina colombiana que considera el derecho de retracto consagrado en el Estatuto del Consumidor como un ejercicio abusivo del derecho ${ }^{15}$, opinión que no comparto, ya que el derecho de retracto no consiste, como este sector de la doctrina lo señala, en una terminación unilateral del contrato por parte del consumidor, sin justa causa; por el contrario, si bien se trata de una terminación unilateral, sus causas están claramente establecidas en la ley, la cual ha establecido que respecto de ciertos contratos donde la posición del consumidor resulta débil, debe protegerse su autonomía privada, con la posibilidad de retractarse de su compromiso cuando evalúa con más calma y prudencia las obligaciones que asumió; por eso la ley no ha establecido el derecho de retracto para todo tipo de contratos, sino sólo para aquellos donde la libertad contractual del consumidor está más restringida, y lo puede llevar a cometer equivocaciones. Es esto lo que sucedió en los dos casos fallados por la sic analizados en este trabajo, donde los pasajeros, al adquirir sus boletos o tiquetes aéreos mediante una compra en la página web de las aerolíneas, cometieron un error al establecer las rutas, error que es excusable y que por ningún motivo puede dar lugar a un enriquecimiento, en este caso sí, sin justa causa por parte de las aerolíneas.

I4 Ver Superintendencia de Industria y Comercio, Oficina Jurídica, Concepto del 28 de marzo de 20I4, rad. I4-032248-0000I-0000.

i 5 Pabón Almanza, C. y Mora Ramírez, A., "Límites al ejercicio abusivo del derecho de retracto. Inconstitucionalidad en la sobreprotección del consumidor", Con-Texto. Revista de Derecho y Economía, Universidad Externado de Colombia, enero-junio, 2014, 67-86. 